\title{
MARIA LUCIA PIMENTEL DE ASSIS MOURA - LIDERANÇA DA ENFERMAGEM FRENTE AO CONSELHO REGIONAL DE ENFERMAGEM DE SÃO PAULO
}

\author{
Edilmar Pereira Vilela Dourado ${ }^{1}$ Evanisa Maria Arone ${ }^{2}$
}

\begin{abstract}
${ }^{1}$ Pós-graduando em Especialização em Gestão em Enfermagem pela Universidade Federal de São Paulo (UNIFESP). Enfermeiro do Programa de Saúde da Família. Bahia, Brasil. E-mail: edilmar_vilela@yahoo.com.br

${ }^{2}$ Doutoranda do Departamento de Enfermagem da UNIFESP. Consultora Técnica do Centro de Estudos da Indústria FANEM. São Paulo, Brasil. E-mail: evanisaarone@hotmail.com
\end{abstract}

RESUMO: Com este estudo objetivamos desvelar a historicidade de uma enfermeira paulista, na presidência do Conselho Regional de Enfermagem de São Paulo, por quatro gestões. Trata-se de uma Pesquisa histórica documental, que teve como fonte de dados os Relatórios de Atividades anuais do Conselho Regional de Enfermagem de São Paulo deste período. Após análise dos dados foi possível identificar o perfil de liderança desta enfermeira frente às questões contemporâneas relevantes para a enfermagem brasileira: a Regulamentação do Exercício Profissional de Enfermagem, o Código de Ética dos Profissionais de Enfermagem, a Sistematização da Assistência de Enfermagem e principalmente, as atribuições deste Órgão de Fiscalização do Exercício Profissional para atender as novas demandas dos Sistemas de Saúde e Educação. Os achados possibilitam inferir que a enfermeira Maria Lucia Pimentel de Assis Moura foi um baluarte na enfermagem paulista e brasileira pela sua brilhante contribuição.

DESCRITORES: Enfermagem. História da enfermagem. Personalidade.

\section{MARIA LUCIA PIMENTEL DE ASSIS MOURA - NURSING LEADERSHIP BEFORE THE REGIONAL NURSING COUNCIL IN SÃO PAULO}

\begin{abstract}
With this study we aimed to disclose the historicity of a nurse born in Sao Paulo who was the chairwoman of the Regional Nursing Council in São Paulo for four terms. It is a historic documentary research which used the Annual Activity Reports from Regional Nursing Council in Sao Paulo of that period as the data resource. Through data analysis, it was possible to identify the leadership profile of this nurse regarding contemporary issues relevant to Brazilian nursing: Nursing Professional Practice Regulation, Nursing Professional Ethical Code, Nursing Care Process, and mainly the attributions of this Agency of Professional Practice Control in attending the new demands of Health and Education Systems. The findings made it possible to presume that the nurse Maria Lucia Pimentel de Assis Moura was a bastion of nursing in Sao Paulo and Brazil through her brilliant contributions.
\end{abstract}

DESCRIPTORS: Nursing. Nursing history. Personality.

\section{MARIA LUCIA PIMENTEL DE ASSIS MOURA - LÍDER DE LA ENFERMERÍA AL FRENTE DEL CONSEJO REGIONAL DE ENFERMERÍA DE SÃO PAULO}

RESUMEN: El objetivo de este estudio es develar la historicidad de una enfermera paulista al mando de la presidencia del Consejo Regional de Enfermería de São Paulo durante cuatro períodos. Es una investigación de carácter histórico documental cuya base de datos fueron los Informes de las Actividades Anuales del Consejo Regional de Enfermería de São Paulo en ese período. Una vez analizados los datos fue posible identificar el perfil de liderazgo de esta Enfermera ante temas contemporáneos importantes para la enfermería brasileña: La Reglamentación del Ejercicio Profesional de Enfermería, el Código de Ética de los Profesionales de Enfermería, la Sistematización de la Asistencia de Enfermería, y particularmente, las atribuciones de este Organismo de Fiscalización del Ejercicio Profesional para atender las nuevas demandas de los Sistemas de Salud y Educación. El resultado del estudio permite inferir que la enfermera Maria Lucia Pimentel de Assis Moura ha sido un baluarte en la enfermería paulista y brasileña gracias a su brillante contribución.

DESCRITORES: Enfermería. Historia de la enfermería. Personalidad. 


\section{INTRODUÇÃO}

Maria Lucia Pimentel de Assis Moura (MLPAM) nasceu em 8 de agosto de 1941 e foi a terceira dos cinco filhos do casal José Mario e Maria Clary, ele um juiz de direito e ela uma professora, católicos fervorosos. Foi descrita pela mãe como: "[...] uma criança dócil, meiga, excelente aluna, tanto em aplicação quanto em comportamento, que tinha uma forma muito especial de escapar das palmadas, dizendo: 'Eu prefiro ficar de castigo' $[\ldots]^{\prime \prime} \cdot 1: 15$

Cursou o ginásio e o colegial com as irmãs Dominicanas, e ao término escolheu, em 1963, fazer o Curso de Enfermagem em Uberaba, Escola dirigida pela mesma congregação e anexa ao Hospital Frei Eugênio, que concluiu em 1966, aprovada com as melhores notas de sua turma. ${ }^{1}$

Formada, regressa para São Paulo e assume simultaneamente dois postos de trabalho em importantes hospitais da capital, com diferentes desafios e oportunidades de desenvolvimento profissional: o Hospital do Servidor Público Estadual - referência em assistência à saúde da época, cujo serviço de enfermagem era considerado modelo, mas ficou pouco tempo, e o Hospital Nove de Julho, onde foi a primeira enfermeira a ser contratada, e permaneceu por trinta anos até a sua aposentadoria. Nessa instituição estruturou não só o serviço de enfermagem como também outras áreas que impactavam diretamente na qualidade da assistência hospitalar prestada. ${ }^{1}$

Enquanto Diretora de Enfermagem do Hospital Nove de Julho, também enveredou para a área da pesquisa, e defendeu o seu mestrado e livre docência, em temáticas relacionadas ao controle de infecção, ambas de extrema relevância e repercussão na prática dos hospitais brasileiros. Sendo que na tese demonstrou que a estufa para esterilização, largamente utilizada até então, não era um equipamento eficiente e seguro. ${ }^{2}$

Neste período ministrou inúmeras palestras e cursos sobre as três temáticas que ela mais se identificava - Administração em Enfermagem, Central de Esterilização e Controle de Infecção e Legislação e Exercício Profissional, pois estavam diretamente relacionadas com as necessidades e preocupações da enfermagem e serviços de saúde brasileiros. ${ }^{2}$

Com o objetivo de se apropriar e contribuir com a temática de recursos humanos e exercício profissional da enfermagem aproximou-se do Conselho Regional de Enfermagem São Paulo (COREN-SP) em 1978. Na ocasião foi convidada, pela então presidente, para colaborar com as questões de Fiscalização que se iniciavam e permaneceu contribuindo com a Entidade, nas duas décadas seguintes.

A importância deste estudo fundamenta-se no fato da enfermeira MLPAM, ser considerada como uma personalidade representativa da Enfermagem paulista contemporânea, que esteve à frente e do COREN-SP em três décadas onde exerceu a presidência em quatro gestões.

MLPAM exerceu uma liderança marcada pela dedicação e empreendedorismo, em um período em que a profissão enfrentou importantes transformações que impulsionaram as conquistas hoje postas. Destacam-se a Regulamentação vigente do Exercício Profissional de Enfermagem Lei Federal No 7.498/1986 e Decreto 94.406/1987; a elaboração e aprovação de um novo Código de Ética dos Profissionais de Enfermagem - Resolução Conselho Federal de Enfermagem (COFEN) - 160 e 163; aplicação do Código de Processo Ético; a Sistematização da Assistência de Enfermagem; o surgimento das Sociedades de Especialistas em Enfermagem; o crescimento significativo dos inscritos devido o incremento de novas escolas e a expansão do processo de profissionalização, redirecionando as necessidades físico-administrativas do Órgão para atender as novas demandas dos Sistemas de Saúde e Educação.

\section{OBJETIVO}

Descrever e analisar a trajetória profissional da Enfermeira Maria Lúcia Pimentel de Assis Moura enquanto liderança da Enfermagem paulista frente à presidência do COREN-SP.

\section{METODOLOGIA}

Estudo exploratório descritivo, Histórico, ${ }^{3}$ embasado em análise documental, tendo como fontes primárias 12 Relatórios de Atividades anuais do COREN-SP, das gestões 1981-1984, 1984-1987, 1990-1993 e 1993-1996. Realizou-se a identificação, seleção e a aquisição do material de estudo, junto ao COREN-SP, por meio de cópia eletrostática dos documentos selecionados. Em seguida foi feita leitura, fichamento e categorização dos assuntos pertinentes, para o objeto do estudo.

Além destes dados utilizamos como fontes secundárias os Boletins Informativos do COREN$\mathrm{SP}$ das respectivas gestões, e documentos do acervo pessoal da enfermeira MLPAM, como o 
Memorial elaborado por ocasião da sua Livre Docência, que possibilitaram resgatar sua biografia e consubstanciar a análise dos dados coletados à luz do contexto, acontecimentos e transformações que marcaram a profissão de enfermagem no período estudado, tendo a sua liderança frente ao Órgão paulista de fiscalização do exercício profissional.

O referencial teórico que adotamos para esta pesquisa se apóia nas idéias dos autores Jacques Le Goff e Peter Burke sobre a história nova ou nova história, cuja base filosófica é a idéia de que a realidade é social ou culturalmente constituída, portanto, precisa ser contada também, a partir de seus sujeitos e contextos. Assim, podemos contar a história de uma pessoa a partir de documentos que produziu, de ações que teve e de idéias que defendeu, em seu tempo. E sob a égide da História Nova, a partir do momento que se busca contar a história de uma pessoa através de documentos, não se considera apenas a coleta e o relato, mas sim, a construção científica do documento cuja análise reconstitui ou explica o passado, contextualizando-se o papel da pessoa ou grupo estudado e seu ambiente. ${ }^{4-5}$

Este trabalho foi realizado no grupo de pesquisa independente do Centro de Estudos e Pesquisas sobre História da Enfermagem - CEPHE.

\section{RESULTADOS E DISCUSSÃO}

\section{O COREN-São Paulo}

Criado pela Lei Federal No 5.905 de 13 de julho de 1973, o COFEN, designou uma junta especial para a instalação do Conselho Regional - COREN-SP em 1975. Para dar cumprimento ao Parágrafo Único do Art. 10, da referida Lei, o COFEN organizou três quadros distintos para fins de inscrição, Quadro I - Enfermeiros e Obstetrízes, Quadro II - Técnicos de Enfermagem e Quadro III - de Auxiliares de Enfermagem, Práticos de Enfermagem e Parteiras Práticas, a qual também determinava que fosse adotado como critério, no que coubesse, o disposto na Lei 2.604/55, de regulamentação do exercício profissional em vigor. ${ }^{6}$

Nos seis primeiros anos, o COREN-SP teve três presidentes, Maria Camargo de Oliveira Falcão - 1975, Victória Secaf - 1976/78 e Yolanda Lindenberg Lima - 1978/81, cujas gestões foram marcadas pelo desafio de inscrever todos os profissionais de enfermagem já existentes no mercado de trabalho e deflagrar o processo de Fiscalização do Exercício Profissional no Estado. ${ }^{7}$
O Conselho é a única entidade de classe em que a vinculação é compulsória, como condição para o exercício da profissão. Além de atuar como poder executivo, tem também competência legislativa - através de provimentos disciplinadores da profissão que tem força de lei sobre os inscritos e judiciária - quando julga em processo ético os profissionais que transgridem as normas do Código de Ética. O Plenário, como órgão máximo de decisões do COREN-SP, é composto por 15 Conselheiros sendo nove do Quadro I, e seis do Quadro II e III, eleitos a cada três anos, por meio do voto direto, obrigatório, onde cada categoria profissional vota na chapa correspondente ao Quadro a que pertence. ${ }^{6}$

Sendo a Autarquia responsável por disciplinar o exercício profissional da categoria de enfermagem, pode-se observar que dentre os maiores desafios enfrentados nas gestões em que a enfermeira MLPAM esteve à frente das decisões do COREN-SP, foram os relativos às questões de Fiscalização da profissão.

No início da primeira gestão 1981-1984, este tema foi abordado de maneira tímida pois as metas iniciais previam a reestruturação do setor de fiscalização da pessoa física e incrementação do setor de registro de empresas, dentro da área da grande São Paulo, como um Plano Piloto. Até porque, neste momento, a fiscalização era feita por meio de dois sistemas, o recebimento de denúncia ou a identificação de problemas no momento do cadastramento de empresas e profissionais. ${ }^{8}$

A realização de um Seminário com representantes de Escolas de Enfermagem e Instituições de Saúde do Estado, para debater como o COREN-SP deveria proceder à Fiscalização, demonstrando a opção por uma atitude sensata e conciliadora, na busca de estratégias e anuência dos pares para encaminhar uma questão relativamente nova e muito complexa até então. ${ }^{9}$

A pesquisa Exercício da Enfermagem nas Instituições de Saúde do Brasil 1982/1983 realizada pelo COFEN e ABEn, demonstrava que a dinâmica do emprego em enfermagem no Brasil era complexa em decorrência da multiplicidade de categorias e dos distintos papéis assumidos, na estrutura das Instituições de saúde, e do forte movimento de terceirização da atividade econômica no Brasil, também representada no setor da saúde, com a consequente proliferação de empregos de baixa qualificação e baixa remuneração. ${ }^{10}$

Outra ação fiscalizatória da época teve como alvo a Imprensa falada e escrita, diante da detur- 
pação do papel profissional do enfermeiro em anúncios, comerciais e novelas. ${ }^{9}$

A sua segunda gestão 1984-1987 teve como meta a implantação definitiva do processo de Fiscalização do Exercício Profissional, em todo Estado de São Paulo, acompanhada da divulgação do papel do COREN-SP, seus objetivos, a questão da fiscalização bem como a verificação da possibilidade de aquisição de um Sistema computadorizado para banco de dados, com o objetivo de agilizar o processo fiscalizatório. ${ }^{9}$

Em 25 de junho de 1986 foi sancionada a Lei Federal No 7.498 que "dispõe sobre a regulamentação do exercício de enfermagem e dá outras providências", 11:11 reconhecendo a profissão de enfermagem, delimitando responsabilidades e estabelecendo quem pode exercer as ações de enfermagem, trazendo novos parâmetros para o processo fiscalizatório, obrigando o COREN-SP a encontrar caminhos para a sua divulgação e cumprimento, tanto pelos profissionais de enfermagem quanto pelos Serviços de Saúde. ${ }^{11}$

Assim recomeça em 1987, o cadastramento de todo o pessoal, que se encontrava no mercado de trabalho, exercendo atividades de enfermagem, sem formação específica, regulada em lei, para a obtenção de autorização legal para esse exercício, com prazo de validade estipulado em dez anos. ${ }^{12}$

A gestão administrativa do COREN-SP dessa ocasião, presidida pela enfermeira MLPAM, buscou se articular com o Sindicato que congregava esse pessoal sem formação específica, mas não encontrou eco junto àquela Federação, dificultando sobremaneira as ações do CORENSP nessa atividade. ${ }^{12}$

Neste período deu-se o início as atividades de fiscalização no interior do Estado, na Região de Ribeirão Preto, com a contratação de dois enfermeiros que conseguiram atingir como resultado: a fiscalização de 157 Instituições e 6.576 profissionais, no primeiro ano de trabalho. ${ }^{12}$

Outro passo importante, foi a contratação de seis fiscais que foram alocadas nas regiões de Barretos, Vale do Paraíba, Litoral Sul, Marília e Grande São Paulo, onde a prioridade foi o levantamento da situação do exercício profissional de Enfermagem nos grandes Hospitais dessas regiões. Cada região tinha suas peculiaridades e as condutas fiscalizatórias variavam de acordo com a realidade local e regional, tendo em vista a oferta de profissionais e recursos das Instituições fiscalizadas. A situação encontrada mais frequente era a presença do Atendente de Enfermagem na chefia dos serviços de enfermagem. ${ }^{12}$

A realização de um encontro com os profissionais docentes das Escolas de Enfermagem, para discutir os problemas éticos da profissão, possibilitou a criação de um grupo de trabalho para aprofundar a questão e organizar o Encontro de Ética de 1986, que aconteceu em maio com o título "Enfermagem - uma profissão como as outras?", em cuja programação foi abordado a Ética e o Ensino e A Ética e o Exercício Profissional. Este período foi marcado pela instalação de várias Comissões de Instrução encarregadas de levantar dados sob fatos éticos. ${ }^{12}$

Em novembro de 1990, MLPAM assumiu novamente a presidência do COREN-SP, cujo Plenário foi empossado por uma Junta Administrativa nomeada pelo COFEN, com base na Decisão COFEN 30/90 que homologou a eleição. Dois conselheiros eleitos não tomaram posse, ficando em vacância duas vagas de Conselheiro do Quadro I, que na chapa eleita, pertenciam a duas enfermeiras da diretoria anterior.

Conforme mencionado no Relatório desse ano: "[...] iniciamos nossa gestão de forma conturbada, pois somente uma semana antes recebemos a informação de nossa posse, não sendo possível nos interar-nos dos principais problemas da Autarquia, nem tido conhecimento prévio de como a estrutura organizacional do COREN-SP, seu quadro de pessoal, previsão orçamentária e outros assuntos importantes, tais como, a existência de atrasos no pagamento de impostos e a falta de condições para arcar com a folha de pagamento dos servidores. [...] defrontamos no mesmo dia de nossa posse com uma greve dos servidores do COREN-SP, marcada para o dia oito de novembro, caso os mesmos não fossem atendidos em sua pauta de reivindicar, entregues ainda na gestão anterior [...]" ${ }^{\prime 3: 26}$

Diante desse impasse, a nova diretoria teve que encontrar medidas imediatas para solucionar a crise que atingia a autarquia, e estabeleceu como metas prioritárias a reorganização administrativa interna da entidade e o inter-relacionamento mais direto com os profissionais de enfermagem. ${ }^{13}$

O Setor de Fiscalização sofreu uma reorganização das atividades das fiscais que passaram a trabalhar com agendamento prévio de suas visitas às Instituições de saúde. Foram criadas duas seções, uma para atender a Grande São Paulo e outra para atender o Interior do Estado, por terem realidades totalmente distintas e necessitarem de 
tratamento diferenciado. As atividades do Setor de Fiscalização foram desenvolvidas sob a coordenação de uma conselheira da Diretoria. ${ }^{14}$

A divulgação da profissão a partir de 1982 foi estabelecida como uma das metas para reativar o Boletim Informativo que passou a ser entregue a todas as Instituições de saúde e Entidades de classe, bem como os profissionais do Quadro I, sendo ampliada posteriormente para os inscritos no Quadro II e III, com a finalidade de conscientizar a população de Enfermagem do desempenho de suas funções. ${ }^{8}$

\section{Gerenciamento das ações}

Já, em sua primeira gestão, teve início a reforma do imóvel da sede própria, que sofreu paralisações devido ao alto custo do material e as taxas inflacionarias vigentes, que inviabilizaram o projeto inicial, exigindo mudanças para adequarse a receita de arrecadação da Entidade. ${ }^{8}$

Reeleita em 1984, a enfermeira Maria Lucia, consegue terminar a reforma da sede, iniciada em sua gestão anterior, o COREN-SP passa a funcionar em sua primeira sede própria, que era espaçosa para a época. Nela, inicia-se o processo de modernização administrativa, necessário para que a fiscalização do exercício profissional pudesse ter infra-estrutura condizente às suas finalidades. ${ }^{9}$

Dentre as dificuldades encontradas nesta gestão, a maior delas foi decorrente da complexidade administrativa da Entidade e o volume crescente de trabalho devido a expansão da Autarquia que exigia recursos tecnológicos na área da informática e atualização contínua dos conselheiros e funcionários. ${ }^{12}$

Com o advento dos processos informatizados já em 1984, a enfermeira MLPAM inicia os primeiros estudos para aquisição de equipamentos e programas, com vistas a obter a autonomia administrativa do COREN-SP, que até então, era gerenciada e realizada pelo COFEN. ${ }^{9}$

Em virtude do aumento vertiginoso de inscritos nos quadros do COREN-SP, o espaço físico ocupado pelo órgão torna-se exíguo, obrigando a expandir-se em outras áreas alugadas, até ter possibilidades de adquirir local próprio para sua expansão, o que é conseguido em 1993, com a aquisição de duas casas contíguas a sua sede..$^{15-16}$

Revistas as metas, foram envidados todos os esforços na ampliação e modernização da administração do COREN-SP, com o objetivo primordial de melhorar o atendimento do profissional, iniciandose em 1994 a ampliação da sede e a reestruturação do sistema informatizado existente. ${ }^{15-17}$
A partir de outubro de 1996, o COREN-SP se instalou em uma moderna sede própria, no mesmo endereço da Rua Dona Veridiana, sendo implantado um sistema informatizado de última geração. $^{18}$

Um acordo feito com a Secretaria de Vigilância Sanitária para a fiscalização conjunta das Instituições de Saúde, principalmente nas cidades do interior do Estado, facilitou as ações e orientações por visita. As ações de fiscalização também foram encaminhadas de forma conjunta com os demais Conselhos da Área da Saúde, que o COREN-SP passou a integrar, junto à Secretaria Estadual de Saúde, desencadeando todo um processo de certificação de responsabilidade técnica dos responsáveis pelos diversos serviços nas Instituições de Saúde. ${ }^{15}$

Cada conselheiro, além das atribuições inerente ao cargo de Diretoria ou Plenária, assumia outra atividade específica de natureza administrativa, para racionalização do trabalho junto com os funcionários do Conselho. Era comum, os conselheiros atenderem os usuários e realizarem visitas fiscalizatórias na capital e no interior de São Paulo, sob a coordenação da MLPAM, que detinha uma ampla visão dos processos de trabalho e suas necessidades. A falta de tempo dos conselheiros para se dedicar a todas essas demandas, foi amplamente discutida nos relatórios, uma vez que não eram liberados de suas atividades profissionais pelas instituições que se encontravam vinculados. ${ }^{12,15,17}$

Um dos grandes problemas encontrados nas gestões da década de 1980, foi a falta de normalização e interpretação das resoluções do COFEN pelos CORENs, gerando diferentes interpretações para os procedimentos, o quê estimulou que a presidente do COREN-SP, sugerisse inúmeras vezes a elaboração de um Manual de Normas e Rotinas e Especificidades Regionais, bem como a insistência da necessidade de desburocratizar as ações do COREN em relação ao COFEN. ${ }^{9}$

Os relatórios além de traduzir os feitos e desafios de cada exercício, expressam sentimentos e sensações de MLPAM, sobre a responsabilidade de estar na direção de um órgão, em processo de construção e agregando desafios, insatisfação, insegurança e até mesmo distanciamento dos principais interessados. MLPAM menciona: “[...] a tarefa por nós abraçada é muito grande e muitas vezes assustamos, com o volume de trabalho existente, com as exigências feitas a nós e com a incompreensão de nossas colegas. Mas mesmo assim, temos tentado, por todos os meios expandir nossas ações acima de nossas limitações de nossos 
desencontros, de nossas recusas, para construirmos nossa profissão, tentando preencher o espaço social que nos pertence e projetar uma imagem positiva de nossa profissão não só aos nossos colegas como também para a comunidade... [...] com tudo isso, perde a classe de enfermeiros o seu prestígio e credibilidade, e alguns grupos por sentirem que o quadro político/econômico do país influencia toda nossa organização social tentam radicalizar posições, dificultando o diálogo, a discussão, e consequentemente, não chegamos a lugar algum $[\ldots]^{\prime \prime} .{ }^{12: 50}$

Um dos grandes problemas enfrentados foi a quantidade de certificados expedidos por Escolas de Auxiliar e Técnicos de Enfermagem para concluintes portadores de certificados de $1^{\circ}$ grau falsos. Isto aproximou a entidade com a Secretaria da Educação, para realização de um trabalho de sindicância junto às Escolas, para anulação dos atos escolares, de grande número de concluintes em processo de inscrição no COREN-SP.

Ao mesmo tempo, havia uma proliferação dos cursos de Atendentes de Enfermagem, que MLPAM menciona como"verdadeiras arapucas de fazer dinheiro, onde os incautos frequentam aulas por seis meses e fazem estágio em várias instituições de saúde. Por conta de toda uma política de contenção de despesas e uma anarquia na estrutura administrativa dessas instituições, estes atendentes têm sido absorvidos pelo mercado de trabalho, por um salário irrisório - normalmente salário mínimo, em substituição a mão de obra qualificada de auxiliares, técnicos e enfermeiras". ${ }^{12: 54}$

Neste período, iniciou-se um trabalho junto com os Órgãos formadores, no sentido de orientá-los sobre a obrigatoriedade da inscrição do recém-formado no Órgão de Classe, condição para exercer a profissão e início da entrega da Franquia Provisória no ato da colação de grau, com a finalidade primordial de divulgar o COREN-SP para a comunidade. ${ }^{12}$

Realizar um trabalho conjunto com as entidades de classe: Associação Brasileira de Enfermagem, União Nacional de Auxiliares e Técnicos de Enfermagem e Associação Brasileira de Educação em Enfermagem, Sindicatos, Secretaria da Educação do Estado de São Paulo, Conselhos Regionais de Profissões Liberais em especial com a ABEn-SP, foi uma meta de todas as suas gestões. ${ }^{12}$

No ano de 1992, o COREN-SP se antecipou a um grave problema de Saúde Pública quando junto com o Ministério da Saúde, organizou seminários sobre o problema da aids em pro- fissionais de Enfermagem, gerando um parecer conjunto com a ABEn-SP. ${ }^{15}$

O COREN-SP também passou a ter uma ação mais efetiva junto a política de cargos e dotação de pessoal de enfermagem nos municípios e no estado. ${ }^{15}$

No ano de 1993, o relatório aponta que a Unidade de Fiscalização tem como meta a melhoria da qualidade da assistência de enfermagem, aproximando-se das Instituições de Saúde, com caráter mais educador do que punitivo. Neste relatório anual encontram-se relacionadas as principais situações irregulares detectadas pelas fiscais em suas visitas fiscalizatórias, devidamente acompanhadas com as respectivas condutas tomadas pelo COREN-SP, o que indica, uma sistematização dos processos de trabalho. ${ }^{16}$

Durante o ano de 1993 foram realizados muitos seminários descentralizados para toda a categoria de enfermagem, sobre a Lei e o Decreto Regulamentador do Exercício de Enfermagem e o Código de Ética de Enfermagem, além de outros aspectos técnicos desejados, pelas comunidades que sediavam os encontros. ${ }^{16}$

Reeleita em 1993, após uma disputa acirrada, com a inscrição de três chapas concorrentes, a enfermeira MLPAM assume a presidência do Órgão através de mandato de segurança impetrado, contra decisão do COFEN 021/93 que anulou o processo eleitoral. O Plenário constituído dos mesmos conselheiros da gestão anterior do COREN-SP tomou posse e estabelece como metas prioritárias a ampliação do processo fiscalizatório com a criação de Delegacias, em especial no interior de São Paulo e litoral, e alocação de recursos humanos específicos para essas áreas. ${ }^{16}$

Surpreendido por uma ação judicial impetrada pelo Sindicato dos Servidores das Entidades Fiscalizadoras do Exercício Profissional do Estado de São Paulo (SINSEXPRO), que exigia o enquadramento dos servidores dentro da Lei $\mathrm{N}^{\circ}$ 8.112/90 sobre o Regime Jurídico Único, o COREN-SP foi obrigado a rever suas metas. A partir de março de 1994 esteve sujeito à sentença judicial que obrigava a contratar pessoal somente mediante concurso público e demissão somente após instauração de processo administrativo, sendo que o COREN-SP recorreu dessa sentença e aguardou por um longo período para reformular seu quadro de pessoal. ${ }^{16}$

Foi no decorrer de 1996 que ocorreu a aprovação e a implementação da decisão do COREN-SP, da obrigatoriedade da existência das Comissões 
de Ética de Enfermagem nas Instituições de Saúde com mais de 10 enfermeiros em seus quadros de pessoal. Essa decisão foi fruto dos inúmeros seminários e reuniões realizadas em todo Estado, em virtude do novo Código de Ética dos Profissionais de Enfermagem. Até outubro deste ano haviam sido formadas Comissões de Ética de Enfermagem em 30 Hospitais no Estado. ${ }^{18-19}$

O processo Fiscalizatório nesta última gestão ficou restrito a apuração de denuncias em virtude do número reduzido de fiscais e da impossibilidade de contratação. Entretanto, consta nos Relatórios o crescente aumento no quantitativo de denúncias, que entre 1992 a 1995, passou de 29 para 560. Consequentemente, a abertura de Processos Éticos instaurados passou de dois para 36, o que demonstra um amadurecimento do trabalho fiscalizatório perante a comunidade, uma vez que os principais problemas encontrados ainda eram: ausência de pessoal qualificado nas instituições e número excessivo de Atendentes de Enfermagem exercendo atividades de Enfermagem. De janeiro a outubro de 1996 foram julgados 45 processos éticos e foi autorizada pelo Plenário a abertura de 48 novos processos. ${ }^{18-19}$

No ano de 1994 foi iniciado em conjunto com a ABEn-SP, a elaboração do Projeto de Pesquisa sobre a Força de Trabalho da Enfermagem no Estado de São Paulo, cujos resultados preliminares foram apresentados no $48^{\mathrm{a}}$ Congresso Brasileiro de Enfermagem realizado em São Paulo. ${ }^{17}$

No exercício de 1995, o COREN-SP possuía cerca de 100 mil inscritos distribuídos nos três quadros funcionais e, quase 70 mil Atendentes de Enfermagem autorizados a exercerem atividades elementares de enfermagem, por já estarem trabalhando na área antes da promulgação da Lei $\mathrm{N}^{\circ}$ 7498/96. Estimava-se ainda, que existia cerca de 120 mil Atendentes de Enfermagem e/ou assemelhados em exercício ilegal da profissão. ${ }^{18}$

Observou-se que em 1996, havia uma preocupação em desenvolver um processo eleitoral que tivesse ampla divulgação a todos os inscritos e instituições de saúde. Houve apresentação de duas chapas e uma delas foi impugnada pela comissão eleitoral, por apresentar irregularidades na documentação solicitada pelo Código Eleitoral. Assim, somente com uma única chapa, as eleições se realizaram por correspondência. Apesar da ampla divulgação, o comparecimento dos votos por correspondência representou menos de $50 \%$ demonstrando pouco interesse da categoria pela Entidade. ${ }^{19}$
Neste relatório é mencionado a não integração do Plenário eleito com o Plenário ainda em Exercício para apropriação das questões pertinentes a transição, como mencionado: "envidamos todos esforços para fazermos uma gestão transitória desde a proclamação dos vencedores até o último dia de nossa gestão, mas não encontramos a receptividade que esperávamos com a nova Diretoria, sendo que conseguimos realizar oficialmente, somente uma reunião conjunta, sendo necessário portanto deixarmos por escrito todas as pendências bem como todos os contratos vigentes, assim como as providências que estavam sendo encaminhadas $[\ldots]^{\prime \prime} \cdot{ }^{19: 5}$

Em 1996 também foi feita a reformulação do Regimento Interno do COREN-SP, para contemplar os diferentes serviços, setores e atribuições, e a partir de outubro, se instalou em uma moderna sede contígua a anterior, o que possibilitou mais conforto e condições de atendimento de usuários e servidores. ${ }^{19}$

O circuito de informações foi contemplado com criação da página do COREN-SP na Internet, o que facilitou o acesso de todos às informações da entidade, e ampliou o seu canal de comunicação inclusive como o correio eletrônico. ${ }^{19}$

Um fato desgastante que envolveu inúmeros desdobramentos jurídicos deveu-se as auditorias realizadas pelo COFEN na jurisdição do CORENSP a partir de 1992, para avaliação do exercício de 1991. Essas auditorias foram realizadas na sede do COREN-SP, e pagas com despesas de passagens e diárias pela própria entidade Regional, por contrariar decisão do COFEN que exigia o envio de toda documentação, contas, comprovantes para sede para realizar auditoria à distância. ${ }^{15}$

Os relatórios de 1995 e 1996 abordam detalhadamente estas questões, e todos os seus desdobramentos jurídicos, observando-se que neste período foi travada uma verdadeira batalha que merece ser tratada em outro estudo, para que possa trazer a tona todos os detalhes e implicações deste embate que chegou inclusive ao Tribunal de Contas da União, e pôde ser acompanhado a posteriore pela a Comunidade de Enfermagem tendo em vista os impasses legais desabonadores vividos pelo COFEN sob a liderança deste mesmo Presidente. ${ }^{18-19}$

\section{CONSIDERAÇÕES FINAIS}

Podemos concluir a partir dos fatos desvelados da trajetória profissional da enfermeira 
MLPAM, enquanto liderança frente ao Conselho Regional de Enfermagem de São Paulo, a condução de um trabalho ousado, corajoso, competente, e compromissado com os ideais e interesses genuínos da profissão, sempre amparado na busca e construção de alianças e parcerias com as demais Entidades de Classe e Instituições, na busca de soluções éticas e eficazes para as necessidades e anseios da profissão de enfermagem e conseqüentemente para o setor da Saúde e Educação.

Concomitantemente, MLPAM teve importante e diversificada participação e contribuição tanto em nível estadual como federal, especialmente com a Associação Brasileira de Enfermagem, Ministério da Saúde, Sociedade de Especialistas, Hospitais e Escolas, onde sempre imprimiu sua marca e idéias na condução de projetos, desenvolvimento de pessoal, organização e implementação de serviços hospitalares.

MLPAM faleceu no dia 9 de novembro de 2007 e deixou um séquito de admiradores, da sua tão honrosa obra.

Agradecemos aos familiares da MLPAM e ao presidente do COREN-SP que possibilitaram o acesso aos documentos imprescindíveis para a realização deste trabalho.

\section{REFERÊNCIAS}

1. Moura MCPA. Minha Vida Vivida com Deus à Luz da Fé. São Paulo (SP): Casa de Edição; 1995.

2. Moura MLP. Memorial apresentado à Escola de Enfermagem Alfredo Pinto da Universidade do Rio de Janeiro [documento acadêmico]. Rio de Janeiro (RJ): UNIRIO; 1989.

3. Padilha MICS, Borenstein MS. O método de pesquisa histórica na enfermagem. Texto Contexto Enferm. 2005 Out-Dez; 14(4):575-84.

4. Le Goff J, organizador. A história nova. São Paulo (SP): Martins Fontes, 1988.

5. Burke $\mathrm{P}$, organizador. A escrita da história: novas perspectivas. São Paulo (SP): Ed. Unesp; 1992.

6. Oguisso T. Organizações Profissionais de Enfermagem. Rev Paul Enferm. 1998 Jan-Dez; 17(1/3):5-14

7. Conselho Regional de Enfermagem Seção São Paulo [página na Internet]. São Paulo (SP): COREN-SP;
2009 [acesso 2009 Fev 11]. Disponível em: http:// www.coren- sp.gov.br/drupal6/

8. Conselho Regional de Enfermagem Seção São Paulo. Relatório do Conselho Regional de Enfermagem de São Paulo - Ano 1982. São Paulo (SP): COREN-SP; 1982.

9. Conselho Regional de Enfermagem Seção São Paulo. Relatório do Conselho Regional de Enfermagem de São Paulo - Ano 1984. São Paulo (SP): COREN-SP; 1984.

10. Conselho Federal de Enfermagem (BR). O exercício da Enfermagem nas Instituições de Saúde do Brasil: 1982/1983. Rio de Janeiro (RJ): Conselho Federal de Enfermagem, Associação Brasileira de Enfermagem; 1985.

11. Conselho Regional de Enfermagem Seção São Paulo. Documentos básicos de enfermagem: enfermeiros, técnicos, auxiliares. São Paulo (SP): COREN-SP; 2000.

12. Conselho Regional de Enfermagem Seção São Paulo. Relatório do Conselho Regional de Enfermagem de São Paulo - Ano 1986. São Paulo (SP): COREN-SP; 1986.

13. Conselho Regional de Enfermagem Seção São Paulo. Relatório do Conselho Regional de Enfermagem de São Paulo - Ano 1990. São Paulo (SP): COREN-SP; 1990.

14. Conselho Regional de Enfermagem Seção São Paulo. Relatório do Conselho Regional de Enfermagem de São Paulo - Ano 1991. São Paulo (SP): COREN-SP; 1991.

15. Conselho Regional de Enfermagem Seção São Paulo. Relatório do Conselho Regional de Enfermagem de São Paulo - Ano 1992. São Paulo (SP): COREN-SP; 1992.

16. Conselho Regional de Enfermagem Seção São Paulo. Relatório do Conselho Regional de Enfermagem de São Paulo - Ano 1993. São Paulo (SP): COREN-SP; 1993.

17. Conselho Regional de Enfermagem Seção São Paulo. Relatório do Conselho Regional de Enfermagem de São Paulo - Ano 1994. São Paulo (SP): COREN-SP; 1994.

18. Conselho Regional de Enfermagem Seção São Paulo. Relatório do Conselho Regional de Enfermagem de São Paulo - Ano 1995. São Paulo (SP): COREN-SP; 1995.

19. Conselho Regional de Enfermagem Seção São Paulo. Relatório do Conselho Regional de Enfermagem deSão Paulo - Ano 1996. São Paulo (SP): COREN-SP; 1996. 